\title{
The Knowledge Map of Sport and Exercise Psychology: An Integrative Perspective
}

\author{
Alexander T. Latinjak ${ }^{1,2 *}$ and Antonis Hatzigeorgiadis ${ }^{3}$ \\ 1 School of Social Sciences and Humanities, University of Suffolk, Ipswich, United Kingdom, ${ }^{2}$ Escola Universitària de la Salut \\ i de l'Esport (EUSES), Universitat de Girona, Salt, Spain, ${ }^{3}$ Department of Physiological Education and Sport Science, \\ University of Thessaly, Trikala, Greece
}

OPEN ACCESS

Edited by: Maurizio Bertollo,

G. d'Annunzio University of Chieti-Pescara, Italy

Reviewed by:

Xavier Sanchez,

Halmstad University, Sweden José L. Chamorro,

European University of Madrid, Spain

*Correspondence: Alexander T. Latinjak a.latinjak@uos.ac.uk

Specialty section:

This article was submitted to Movement Science and Sport Psychology, a section of the journal Frontiers in Psychology

Received: 31 January 2021 Accepted: 21 May 2021

Published: 16 June 2021

Citation:

Latinjak AT and Hatzigeorgiadis A (2021) The Knowledge Map of Sport and Exercise Psychology: An Integrative Perspective.

Front. Psychol. 12:661824. doi: 10.3389/fpsyg.2021.661824
The present work contains a personal perspective on what sport and exercise psychology (SEP) is today. It is a global synthesis of research about psychological aspects related to the context and practice of sport and exercise. The intended impact was to positively influence teaching SEP to students, to promote interdisciplinary research and practice, and to assist the development of SEP as an applied science by helping experts develop a more holistic view of the field. Over 650 theoretical and review articles about psychological concepts in connection to sport and exercise were read in the process of creating a conceptual model that reflects the essence of SEP and leads to a conceptualization of SEP based on research topics. The result was a knowledge map of SEP made up of four main research clusters: biopsychological descriptors, external variables, psychological skills, and applied SEP practice. In terms of interdisciplinarity, the present perspective on SEP suggests that sport and exercise can be used as a research paradigm or natural laboratory to study psychological aspects relevant to various scientific fields, and that sport and exercise can be used as a therapeutic framework in response to challenges that researchers and practitioners in these fields are typically addressing.

Keywords: athlete, mental skill, metascience, performance, physical activity, theory

\section{INTRODUCTION}

Sports and exercise psychology (SEP) has grown rapidly, much like some cities during the industrial revolution. New neighborhoods have emerged one after the other, and the familiar face of the old towns has dissolved into something equally bewildering and exciting. Yesterday's SEP provides a rich legacy (see Vealey, 2006), but the development of tomorrow's SEP could benefit from an urban map that shows what has been done and what can and needs to be done. Although the European Federation for Sport and Exercise Psychology (FEPSAC) celebrated in 2019 already its 50th anniversary, as did the International Society for Sport Psychology (ISSP) in 2015 (for an historic overview see, Elbe et al., 2019), sport psychology is only the 47th of 56 subdivisions of the American Psychological Association (APA). Nevertheless, SEP has matured, into a rapidly expanding field of psychology (Raab, 2017) spreading across many other scientific disciplines and psychological subdisciplines. SEP reached already from high performance, to education, to counseling, to organizations, to feminism, to health, to aging, to medicine, to neuroscience... As a result, there has been enough development to recognize research trends and interests to draw 
a map of the research landscape in SEP and provide an answer to what SEP is today.

\section{Aims and Scope}

The aim of the present work was to present an integrative personal perspective of research on psychological aspects related to the context and practice of sport and exercise, published in SEP journals as well as other journals in psychology, sports sciences, and other scientific fields. The intended impact of this work was to positively influence teaching SEP to students, promoting interdisciplinary research and practice, and assisting the development of SEP as an applied science by helping experts develop a more holistic view of the field. SEP was initially introduced as a subject in psychology, sports science, and education in bachelor's and postgraduate courses, later as an independent postgraduate qualification in master's courses, but also in professionalization courses for coaches in various sports, while bachelor's degrees in SEP were recently developed. As lecturers, a pedagogical tool in the form of a schematic model of SEP topics could help present SEP as a scientific area and introduce and contextualize module contents. In addition, when students have to decide which modules to take or to which topics they want to write their dissertation, a schematic model of SEP topics could also help them to make more informed decisions about their academic development.

Psychologists from diverse psychological disciplines have wondered if research in SEP could influence the development of their own area (Furley, 2019). In fact, the relationship between SEP and other disciplines of psychology has been intense and beneficial in a reciprocal way. On the one hand, SEP has resorted to other disciplines of psychology by applying important theories, for instance, from cultural (Ryba, 2017), clinical (Moore and Bonagura, 2017), educational (Holt et al., 2017), evolutionary (Balish et al., 2013), ecological (Araújo et al., 2019), and health (Biddle and Fuchs, 2009) psychology to the context of sports and exercise. On the other hand, SEP research can inform the research development in other areas of psychology (e.g., Shoenfelt, 2016). An integrative perspective of SEP research could facilitate the cross-pollination of the SEP literature across different psychological and other sciences to stimulate integrative theories and interdisciplinary research and practice.

For researchers who already study psychological aspects related to the context and practice of sport and exercise, an integrative perspective of the SEP research landscape can be a useful tool to discuss certain topics or results in the light of the broader literature. Given the rapid growth of SEP, especially early career researchers may find it difficult to consider the complex nomological network of concepts in which the variables of their study are embedded. SEP experts are facing an insurmountable number of publications on a variety of topics that leads many researchers to retreat into niche areas of expertise (Neimeyer et al., 2012) or insular camps (Bevan, 1991). The present work could assist researchers and practitioners to link their areas of expertise to other topics and discover new growth areas that respond to new societal challenges.

In terms of originality, apart from some introductory book chapters (e.g., Eklund and Crocker, 2019), only few global syntheses of research in SEP have been published since the beginnings of this scientific field (e.g., Browne and Mahoney, 1984). Regarding contemporary syntheses, for example, two bibliometric-review studies were conducted, on 1140 and 2276 articles, respectively (Lindahl et al., 2015; Németh et al., 2016). In both reviews, motivation, coping with anxiety and stress, physical activity behavior change, and methodological issues were identified as the most recurrent topics in SEP. Despite the undeniable contribution of these bibliometric-review studies, they identified popular research trends rather than summarizing what SEP is today (see also, Biddle, 1997; Weiss and Gill, 2005; Rhodes and Nasuti, 2011). The aim of the present work was to present a perspective of the SEP research landscape in which the key concepts found in theoretical articles and reviews are synthesized regardless of their popularity, in order to coherently reflect the scope of the SEP research in a thematic model. Furthermore, such a synthesis should also reveal the fundamental attributes required for a conceptualization of todays' SEP based on the breadth of research topics.

\section{THE KNOWLEDGE MAP OF SPORT AND EXERCISE PSYCHOLOGY}

The perspective presented here is the result of a process similar to the three-stage model of the creative process in science by Scheffer et al. (2017): First, different inputs are collected; then these inputs are combined to novelty; finally, the result is crafted into an innovative product. In the present case, studying literature contributed to the end product along with a range of less conventional activities, including informal discussions with very different groups of people, long walks and daydreaming, and sketching models in different artistic ways. These activities might be met with skepticism in psychology, but some researchers believe they should be viewed as part of the scientific method (Scheffer et al., 2015). In addition, the view adopted in the present project accepts "a world of multiple, constructed, and thought-dependent realities" (i.e., ontological relativism; Sparkes and Smith, 2009, p. 493). Hence, it was assumed that there is no true way of explaining what SEP is. Instead, there are many idiosyncratic perspectives that can serve individuals to explain SEP to themselves and others.

\section{The Development of the Knowledge Map}

The project began with making time for thinking and informal discussions about, and extensive reading of, 662 mostly theoretical papers and reviews that were published in SEP journals as well as in journals from psychology, sports science, and other areas (e.g., medicine or sociology). Different mental models were created and tested against each other, while reading, mindwandering, and discussing with SEP experts, other psychologists as well as coaches and athletes about what SEP is about today.

During the development of the current perspective on SEP, the conceptual map in Figure $\mathbf{1}$ was created. SEP was placed in the center of the map, and initially a key distinction was made between two distinct but closely related goals 
of SEP: understanding experiences related to wellbeing and performance in sport and exercise (Biddle, 1997) and improving those experiences through applied SEP practice (Portenga et al., 2017). The model was further developed by recognizing that experiences related to wellbeing and performance in sport and exercise consist of internal and external variables (Massey et al., 2013). In addition, internal variables include both the descriptive attributes and processes of people and their psychological skills (Dohme et al., 2017). Based on the previous decisions, an outline of the knowledge map of SEP was drawn up in which SEP research concepts can be summarized in four clusters: (a) biopsychological descriptors, (b) external variables, (c) psychological skills, and (d) applied SEP practice.

With regard to the four basic clusters, topics could be identified that further organize SEP concepts. Biopsychological descriptors help answer the questions of who people are (e.g., with personality traits) and how they are in certain situations (e.g., with emotion concepts). External variables help answer the questions of where people are and what they interact with (e.g., description of sports facilities and equipment), who they are with (e.g., description of social networks), and what they do (e.g., description of task constraints). Psychological skills include concepts that refer to what people do to regulate themselves (e.g., through relaxation skills), what people do to regulate others (e.g., through modeling skills), and what people do to regulate both themselves and others (e.g., through emotion control skills). Finally, applied SEP practice research contains concepts that explain how practitioners define practice (e.g., through humanistic approaches), how practitioners work (e.g., in interdisciplinary teams), and what practitioners do (e.g., quiet eye training). In Figure 1, a selection of five examples was added to each sub-category to illustrate where a particular SEP concept might fit.

After elaboration, the conceptual map (Figure 1) was presented to SEP experts in conferences and informal meetings, to applied practitioners, physical education teachers and coaches in workshops, and to students in bachelor and master's degrees. The aim was to further develop mental representations of the four main clusters and their connections to form a SEP model. The final Knowledge Map of SEP (Figure 2) was created through reading to prepare visual and written materials (e.g., this article and the figures in it), presenting the conceptual map (e.g., in conferences), and receiving positive feedback and constructive criticism (e.g., from SEP experts). Biopsychological descriptors are at the center of the knowledge map. The perception and appraisal of external variables shapes biopsychological descriptors, and biopsychological descriptors influence external variables through behavior and performance. This circular relationship can be modulated when self-awareness and metacognition trigger the use of psychological skills, the quality of this process being summarized in concepts such as resilience, mental toughness, or self-control. Finally, applied SEP practice can influence all other three clusters. The following sections detail the knowledge

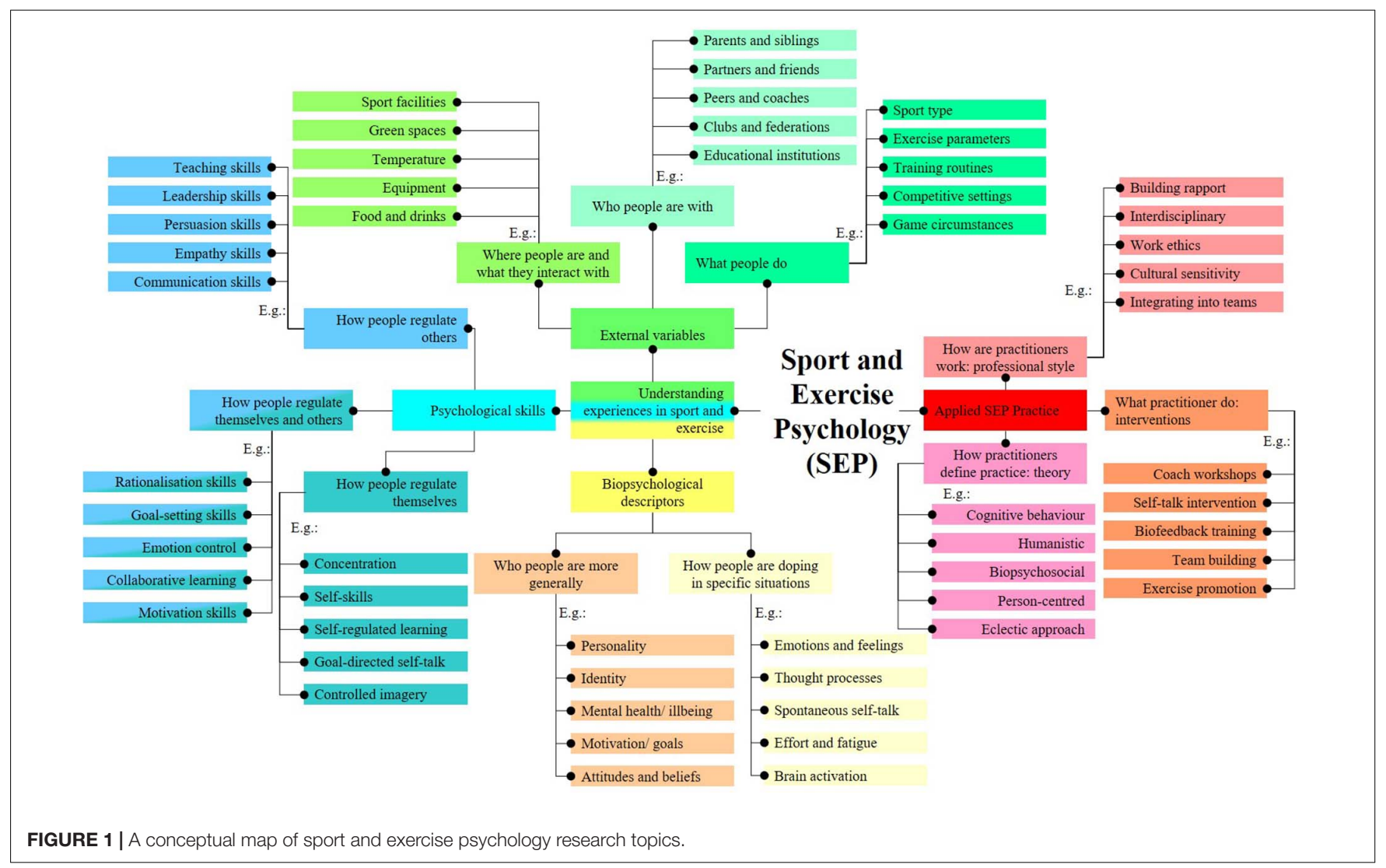




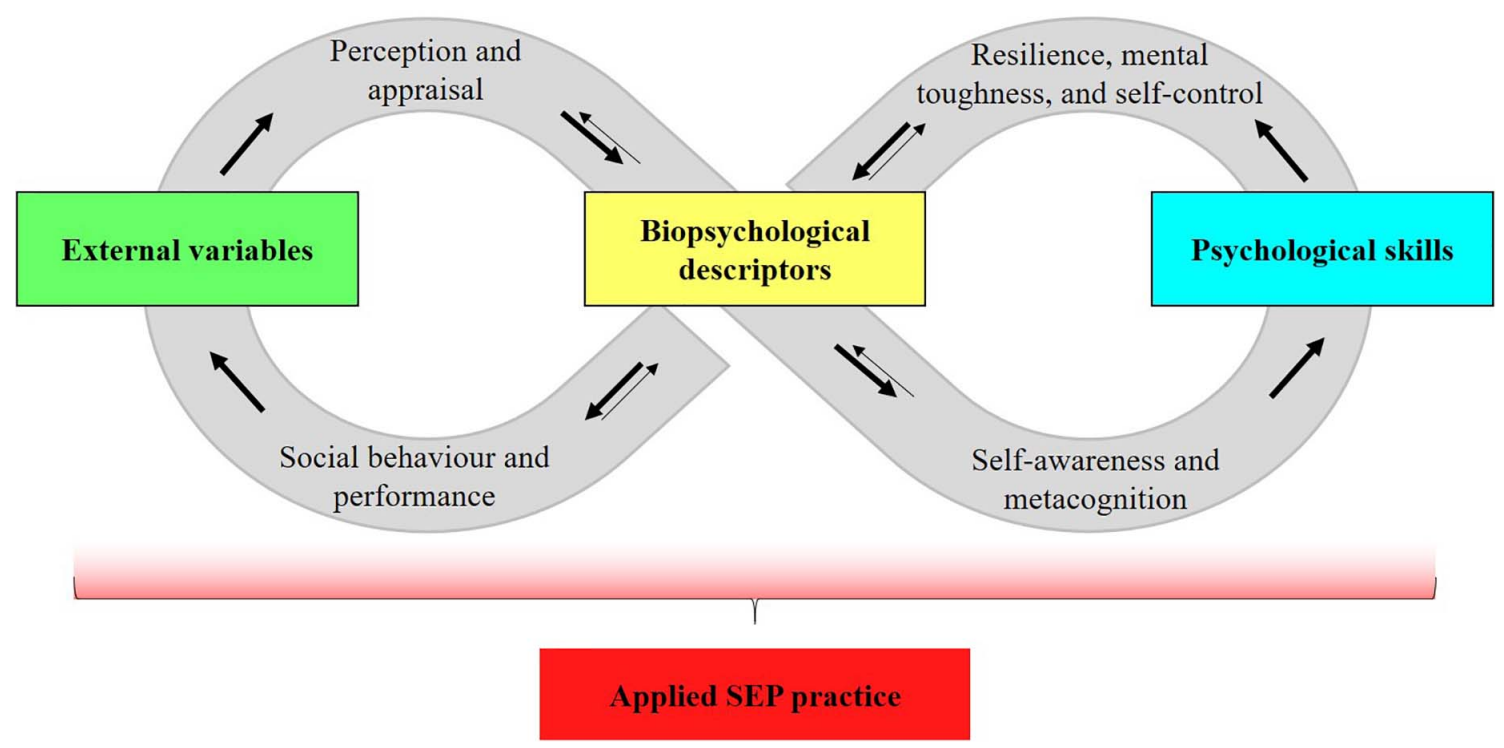

FIGURE 2 | The knowledge map of sport and exercise psychology.

map by describing each major cluster and the relationships between them.

\section{Biopsychological Descriptors}

Biopsychological descriptors are at the center of the present knowledge map because they describe how people are at certain moments and who people are in general. The cluster includes physical (e.g., height), physiological (e.g., oxygen consumption), and psychological variables (e.g., vigor) with highly variable temporal stability [i.e., processes (e.g., sadness) and attributes (e.g., personality)], which are inevitable building blocks for the experience of life. These concepts describe individuals or collectives in certain time frames, ranging from milliseconds (e.g., an adrenaline boost) to decades (e.g., a groups' social identity). The list of concepts within this cluster is long and heterogeneous. In order to outline the conceptual landscape in SEP, it was important to find further subdivision criteria to summarize the list of biopsychological descriptors. Three partly overlapping criteria can help gain an overview of this cluster.

First, in this cluster fit physical, physiological, and psychological variables (also, anthropometric, physiological, and psychological characteristics; Baker et al., 2020), although these categories are of course not always mutually exclusive. In SEP, researchers have studied physical variables that describe people from a structural perspective within the sport and exercise context, including anatomical aspects in the brain and the rest of the body, for example, linked to an injury (Bogardus et al., 2019) or to people's gender (Jason et al., 2015). Further, researchers have also included physiological variables that describe people on a biological functioning level, including hormonal responses (Cooke, 2013) and specific neurocognitive mechanisms (Cross et al., 2014). Although many experiences in sport and exercise could potentially be explained in terms of their physical and physiological underpinnings, SEP researchers still rely heavily on more functional psychological variables that describe people (Cross et al., 2014). For instance, concepts such body image (Srismith et al., 2020), motivation (Clancy et al., 2017), emotion (Friesen et al., 2013), beliefs (Jordana et al., 2020), and attitudes (e.g., toward doping; Morente-Sánchez and Zabala, 2013) are necessary to make sense of the uncountable interactions on a physical and physiological level in the human body.

The second criterion to organize biopsychological descriptors is related to their temporal stability. These categories are gradual and not categorically separated. Relatively stable aspects of people in or related to the context of sport and exercise are trait-like attributes and include for example age (Webdale et al., 2019) and habits (Hagger, 2019), as well as aspects related to mental health (Gucciardi et al., 2017). Rapidly changing aspects of people are state-like processes, and include, for example, conflict (Wachsmuth et al., 2017), effort (Pageaux, 2016), and attention (Moran, 2012).

Lastly, biopsychological descriptors characterize individuals and groups, the latter ranging in numbers from two individuals to broad societies. Emotions, for instance, are individual psychological processes, though they are influenced by others or similar to those that others experience at that moment (Campo et al., 2019). Motivational climate, on the other hand, is clearly a collective psychological attribute (Harwood et al., 2015), because it is not located within a single person. Overall, the cluster biopsychological descriptors includes the wide diversity of individual and collective physical, physiological, and psychological processes and attributes that describe people in and beyond the sport and exercise context.

\section{Section Summary}

Regarding biopsychological descriptors, it is apparent that the central focus of SEP is not limited to explaining who people are in sport and exercise contexts. SEP is equally 
concerned with understanding who people are from a holistic perspective (Stambulova and Wylleman, 2019) that transcends the boundaries of the world of sport and exercise. With relevance to interdisciplinary research, it should be noted that biopsychological descriptors studied in SEP are very similar to those in other areas of psychology and that the sport and exercise context may offer a special opportunity to study human nature. Many of the cultural layers present in other everyday activities often disappear in sport and exercise to reveal more primary, more rudimentary aspects of human behavior (Furley, 2019). As to future SEP research, one challenge is to uncover increasingly more biological foundations of popular psychological concepts. SEP research has already been working intensively on the measurement of psychological processes and attributes (Lindahl et al., 2015; Németh et al., 2016). In this context, understanding the biological bases of psychological concepts will become increasingly important to better study and measure these processes and attributes, and in particular the relationship between them.

\section{External Variables}

According to SEP research, it is often the sport and exercise context that largely determines people's psychological experiences. Increasingly popular cultural (Ryba, 2017) and socioecological approaches (e.g., Zhang and Solmon, 2013) have placed emphasis on external variables and their impact on biopsychological descriptors. Given the variety of external variables that affect people in the context of sport and exercise, including aspects as diverse as altitude of a geographic location or consequences of task failure, subcategories were needed to outline this cluster. Inspired by the categories proposed by other authors in broader literature reviews (e.g., Zhang and Solmon, 2013; Sarkar and Fletcher, 2014; Laborde et al., 2018; Bogardus et al., 2019; Webdale et al., 2019), external variables were grouped into three areas: physical environment, social and organizational influences, and task characteristics and competitive factors.

In SEP, the physical environment has been studied mainly as an antecedent or determinant of diverse biopsychological descriptors. Zhang and Solmon (2013) argued that selfdetermined motivation to practice physical activity is influenced by variables such as availability and convenience of physical activity facilities, safety of physical activity settings, or physical activity equipment. Laborde et al. (2018) included aromas, lights, sounds, temperature, outdoor environment, and altitude as examples of physical-environmental variables that affect cardiac vagal activity. Furthermore, Paulus et al. (2009) provided evidence that extreme cold or high altitude might be other aspects of athletes' physical environment that can have profound effects on cognitive and behavioral processes.

Social and organizational variables used in SEP can be arranged according to the Socio-Ecological Model (e.g., Balish et al., 2014; Bogardus et al., 2019), distinguishing between the interpersonal, organizational, community, and policy level. On the interpersonal level, coaches, parents, and peers, for example, play a significant role in shaping youth sport experiences (Sheridan et al., 2014). On the organizational level, Roberts et al. (2019) identified variables such as power imbalance, conformity to dominant values, organizational tolerance, or deficient internal communication as factors related to non-accidental violence in sport. On the community level, relationships among organizations, institutions, and social networks or standards in a defined area are variables affecting health behavior (Zhang and Solmon, 2013). Finally, on the policy level, variables such as economic incentives, gender equity policy, and health and safety requirements were related to youth sport attrition (Balish et al., 2014).

Task characteristics and competitive factors include demands of a physical activity, such as whether or not task success is dependent on strength, speed, agility, flexibility, technical ability, as well as objectives and rules of a sport (Webdale et al., 2019). More specifically, Ometto et al. (2018) listed number of players involved, field dimensions and locations of play, number of goal-scoring targets used, and rules, among others, as variables that shape individual and collective tactical behaviors. Regarding more competitive factors, Sarkar and Fletcher (2014), for instance, identified match importance, score status, and momentum as variables related to stress in athletes. Finally, in research, diverse experimental conditions, such as pressure simulation tasks (Kent et al., 2018) or the Vienna Test System (Ong, 2015), are also part of task characteristics and competitive factors.

For external variables, a concept to enter this cluster should include objective and observable events rather than subjective perceptions and interpretations. The actual behavior of coaches would therefore be part of external variables, while the perception of their coach's support by athletes would not be part of this cluster. Concepts that allude to how external variables are perceived and appraised by people fit in the cluster placed on the link between external variables and biopsychological descriptors (see next subsection). The importance of this detail in reality is best illustrated by the frequent lack of associations between observations and self-reports by athletes on coach behaviors (Smith et al., 2016).

\section{Connecting Biopsychological Descriptors and External Variables}

Some concepts that did not fit clearly into either biopsychological descriptors or external variables helped explaining the link between the two clusters. In the knowledge map, a bidirectional path connects biopsychological descriptors and external variables, and the concepts that describe these paths are necessarily, to some extent, both biopsychological descriptors and external variables. SEP research has studied a continuous circle in which external variables (e.g., a repetitive task) influence how and who people are (e.g., distracted), which in turn has an impact on external variables (e.g., coach's negative reactions).

Some of the dominant theories in SEP explain parts of the interaction between external variables and biopsychological descriptors. For example, ecological dynamics to decision making assumes that behavior emerges from the performer-environment system and that both performer and environment continuously shape one another (Araújo et al., 2019). Self-determination theory suggests that the motivation to engage in physical activity is shaped by the physical and social environment in 
which physical activity takes place (Ng et al., 2012). Finally, flow theory describes the psychological process that involves intense focus and absorption in a particular activity, in which athletes are in harmony with their task environment without the need for effortful controlled mental processes (i.e., use of psychological skills; Swann et al., 2018). Overall, it can be assumed that the dynamic relationship between external variables and biopsychological descriptors has been one of the major research interests of SEP.

\section{External variables $\rightarrow$ biopsychological descriptors}

Some specific concepts refer to the influence of external variables on biopsychological descriptors which has been a central SEP research area (Zhang and Solmon, 2013; Ryba, 2017; Bogardus et al., 2019). Perception and appraisal are two concepts on this auxiliary cluster in the knowledge map. Both perception and appraisal are biopsychological descriptors that, among other things, link external variables (e.g., explicit task demands) with other biopsychological descriptors (e.g., neurologic activations in the limbic system).

In SEP research, perception had a higher physiological character in relation to basic external variables (e.g., thermal perception, Stevens et al., 2018; or visual perception, Renshaw et al., 2019) and a greater psychological character in relation to more complex external variables (e.g., perceived autonomy support, Gillison et al., 2019; or perceived safety of sport facilities, Hanlon et al., 2019). Appraisal variables inform about whether external variables are interpreted as supportive or demanding (Arnold and Fletcher, 2012), or, alternatively, as challenging or threatening (Meijen et al., 2020). Although the knowledge map primarily indicates that perception and appraisal mediate the effects of external variables on biopsychological descriptors, in reality at least the relationship between biopsychological descriptors (e.g., emotions) and perception and appraisal (e.g., challenge appraisal) is bidirectional.

\section{Biopsychological descriptors $\rightarrow$ external variables}

Some concepts that are inseparable from biopsychological descriptors are equally defined by their impact on external variables. To schematize SEP research, these concepts can be divided into social behavior and performance. Social behavior was defined here as verbal and non-verbal behavior that is perceptible to and has an impact on others. This list includes, among others, emotion expression (Friesen et al., 2013), communication (Beauchamp et al., 2005), leadership behavior (Cotterill and Fransen, 2016), doping (Ntoumanis et al., 2014), gambling (Derevensky et al., 2019), prosocial or anti-social behaviors (Kavussanu and Al-Yaaribi, 2019), and sport activism (Cooper et al., 2019; Valiente, 2019). Each concept in this list is part of the dynamic relationship of biopsychological descriptors, and necessarily affects external variables. For example, sports activism helps raise others' awareness of social injustices in a broader social context (e.g., Colin Kaepernick), and doping can affect the popular image of an athlete, sport, or competition (e.g., Lance Armstrong, cycling, Tour de France).

Performance is probably one of the most central variables not only in SEP but in some of the psychological sciences and most of the sport sciences (Glazier, 2017). In most studies, performance is used as a generic concept that is defined by the way in which it is operationalized or measured (e.g., time to completion in a cycling time trial or the ISU Judging System used to judge the figure skating disciplines). Participation in physical activity and, conversely, sedentarism are two basic performance variables (Strain et al., 2019). Relatively stable changes in performance over time indicate skill acquisition (Kumari et al., 2019) or motor skill learning (Chen et al., 2018). In addition, situation-specific performance concepts include clutch performance (Swann et al., 2018) and choking (e.g., Carson and Collins, 2016), which refer to superior and inferior performance under pressure, respectively. Performance (e.g., winning a triathlon), like social behavior, is determined by biopsychological descriptors (e.g., effort and positive attitude) and materializes through changes in external variables (e.g., time on a clock, prize money, followers in social media, and world ranking). Once more, the representation in the knowledge map is simplistic, and at least the link from of biopsychological descriptors (e.g., empathy) to social behavior (e.g., prosocial-behavior) and performance (e.g., cooperation attempts) is bidirectional.

\section{Section Summary}

The discussions about external variables and their relation to biopsychological descriptors showed that SEP research has focused intensively on the ongoing cycle in which external variables affect individuals and collectives, and conversely, individuals and collectives influence external variables, especially through social behavior and performance. The fact that the external variables in SEP research, including typical sports and exercise tasks, influence the biopsychological descriptors that are also critical to other psychological disciplines suggests that sport and exercise can be useful as an alternative experimental paradigm. Thus, sports and exercise can be a natural laboratory for the study of psychology constructs (e.g., Sarkar and Fletcher, 2014).

Regarding future avenues for SEP research, beyond performance, scholars need to explore contemporary ways in which athletes influence their environment. For example, it is time to seriously consider how athletes influence their environment by becoming political actors (Valiente, 2019). Some athletes are challenging global societal issues and injustices such as climate change, gender inequalities, racism, sexual discrimination, or social exclusion of minorities (e.g., Cooper et al., 2019), and their actions merit researchers' attention.

\section{Psychological Skills}

Popular concepts in SEP research describe people's resources to control and adjust some of their biopsychological descriptors. These resources have often been called psychological skills (also mental skills; e.g., Bányai et al., 2019). Psychological skills have long fascinated SEP researchers (Singer, 1976), possibly because they are related to the power of self-control and because, like technique, tactics, and physical condition, they can be trained (Vealey, 1988). Despite its popularity, the concept of psychological skills has fewer clear boundaries to biopsychological descriptors compared to the boundaries 
between those processes and attributes and external variables. In fact, biopsychological descriptors as well as psychological skills are part of people's inner world, while external variables are part of the outer world. Therefore, the process of placing specific concepts in the cluster implicitly required a working definition of psychological skills and the description of their relationship to biopsychological descriptors.

In this work, psychological skills were conceptualized as learned intentional mental processes that control biopsychological descriptors (e.g., emotions), either to regulate those descriptors (e.g., control emotions to cope with anxiety) or to indirectly influence related descriptors (e.g., control emotions to improve attention). This conceptualization was based in parts on works like Vealey (1988), Dohme et al. (2017), and Portenga et al. (2017). To some extent, the use of psychological skills could be described as doing what one always does, but in a different way or at a different time than one would automatically or spontaneously do. In SEP, some authors have already differentiated between specific spontaneous and controlled processes (e.g., spontaneous and goal-directed self-talk; Latinjak et al., 2019). Notwithstanding the usefulness of the distinction between biopsychological descriptors and psychological skills for the purposes of the present project, caution should be exercised in distinguishing between uncontrolled and controlled processes in real life. For example, while in research the distinction between spontaneous and goal-directed (i.e., intuitive and rational) self-talk is useful, in reality the former may have some controlled rational components and the latter may be biased by spontaneous emotional aspects. Hence, although the idea of dual processes, one uncontrolled and the other controlled, may appeal seductive, the differences between biopsychological descriptors and psychological skills are in reality to be understood as a proportion difference instead of a categorical difference (Furley et al., 2015; Melnikoff and Bargh, 2018).

Specific concepts in the cluster of psychological skills differ in complexity. For example, aspects of executive functioning such as working memory, inhibitory responses, cognitive flexibility, willpower, planning, and attention control (Audiffren and André, 2015) are relatively concrete skills. However, other skills are far more complex. SEP includes research on more complex intrapersonal psychological skills including those related to emotion-control (Friesen et al., 2013), self-motivation (Chuckravanen et al., 2019), or imagery (Toth et al., 2020). In SEP more complex interpersonal psychological skills including those related to leadership (Cotterill and Fransen, 2016), persuasion (Jackson et al., 2020), or cooperative learning (Casey and Quennerstedt, 2020) have also been studied.

\section{Connecting Psychological Skills and Biopsychological Descriptors}

Across the SEP literature, there appears to be broad consensus that the extent to which psychological skills (e.g., leadership skills) effectively adapt some of the biopsychological descriptors (e.g., team goals) to various external variables (e.g., the score line) is critical to explaining sport performance and exercise behavior (e.g., Norris et al., 2017; Barcia et al., 2019; Liew et al., 2019). The use of psychological skills mediates the circular relationship between external variables and biopsychological descriptors. For example, coach criticism perceived by athletes as a threat can trigger muscle tension, which leads to performance decline and further criticism, unless athletes become aware of their threat appraisal or muscle tension and use psychological skills to regulate one or both to enhance performance.

Ideally, experiences like clutch performance automatically come from experiences, like flow states (Swann et al., 2018), in which the individual is in harmony with their environment. The multiaction plan model identifies this as Type I performance, characterized by automated control (Bortoli et al., 2012). If necessary, however, conscious self-regulation can lead to positive performance (i.e., Type II performance characterized by deliberate control) in two ways. Deliberate control can help create harmony (e.g., flow states) and it can effortfully prevent or counteract the negative effects of non-harmonious relationships with the environment on biopsychological descriptors. In the former case, for example, self-acceptance skills (Moore, 2009) can be important in creating flow. In the latter case, continuous efforts at self-regulation, even if they are effective at first, lead after some time to states of ego depletion (Ong, 2015). Hence, some researchers have promoted skills such as self-acceptance, which create harmony over skills used with change-oriented intentions (e.g., Birrer and Morgan, 2010).

Given the importance of psychological skills for the selfregulation of biopsychological descriptors, it is not surprising that very popular concepts can be found in both directions between the two clusters. All of these concepts have in common that they are to a certain extent defined by uncontrolled and controlled components of psychological experiences.

\section{Biopsychological descriptors $\rightarrow$ psychological skills}

Some concepts used in SEP are, to a certain degree, a descriptor of how people are and who people are, and a trainable ability related to self-regulation. Self-awareness (Mareš, 2019) and metacognition (MacIntyre et al., 2014) are two such concepts, that have an automatic component, like biopsychological descriptors do, but which are also part of self-regulatory processes, similar to psychological skills. Metacognition, for instance, includes metacognitive experiences that are more automatic feelings and judgments, and metacognitive skills that relate to more intentional planning, monitoring, and reviewing of task execution (for more detail see, Brick et al., 2016). These concepts at the interface between biopsychological descriptors and psychological skills (e.g., injury awareness; Chen et al., 2019) seem to be important in explaining how certain biopsychological descriptors (e.g., pain) trigger the use of psychological skills (e.g., exercise intensity control). Yet, to some degree at least the relationship between biopsychological descriptors, and selfawareness and metacognition is bidirectional.

\section{Psychological skills $\rightarrow$ biopsychological descriptors}

Other concepts at the interface between biopsychological descriptors and psychological skills describe the effectiveness of skills to control descriptors. Popular terms used to describe the quality of self-regulation were mental toughness (Gucciardi et al., 2017), resilience (Sarkar and Fletcher, 2014), and self-control 
(Englert et al., 2020). Mental toughness may be best to exemplify the mixture of descriptive processes and attributes and learned skills that compose these concepts. According to Liew et al. (2019), mental toughness is determined by inherited attributes (e.g., self-efficacy, positivity, or mental self-concept) and by learned skills (e.g., attention control or handling pressure). Furthermore, resilience refers to the positive responses to setbacks, obstacles, and failures that are essential to athletic success (Galli and Gonzalez, 2015). Self-control refers to the self's capacity to exert control over thoughts, emotions, and behaviors (Baumeister et al., 2007). Research in SEP has linked the study of psychological skills also to failures in the process of selfregulation inserting the idea of ego depletion into the literature (e.g., Ong, 2015).

\section{Section Summary}

The discussions about psychological skills and their connections with biopsychological descriptors revealed that large parts of SEP research conceptualize individuals and collectives as inherently autonomous actors. As such, people play an active role in the regulation of their own biopsychological descriptors through the interaction of metacognition and psychological skills and take responsibility for their performance and their societal impact. Sport and exercise are a natural environment in which recurring psychological challenges stimulate the use and development of psychological skills. For example, young athletes need to learn to deal with fatigue, anxiety, defeat, boring routines, conflicts, inferiority, and deselection, as these are regular psychological challenges in sports and exercise (Sarkar and Fletcher, 2014). Successful individual or collective coping with these challenges strengthens the psychological skills young athletes can transfer into other areas of life (Kendellen and Camiré, 2019). Overall, SEP has provided a wealth of evidence to consider sport and exercise as potentially socializing contexts and activities (e.g., Ronkainen et al., 2020).

There is a need for further research into the delicate balance between (a) creating psychological challenges (e.g., task failure) that are essential for the development of psychological skills (e.g., self-learning skills) and (b) protecting particularly younger athletes from negative sports and exercise experiences (e.g., burnout). When psychological challenges become insurmountable, they can lead to mental illness, including burnout (Gustafsson et al., 2014) or eating disorders (Bar et al., 2016), instead of skill development. Sport and exercise psychologists have worked together with policy makers in protecting athletes from potentially harmful external stressors (e.g., combining anti-discrimination policy implementation with gender and sexual diversity education, Kavoura and Kokkonen, 2020).

What remains is the controversial question of whether positive changes in sports and education policies (Reeve, 2009), as well as in coaching and teacher education (Smith et al., 2016), have unintentionally restricted young people's need for some of their psychological skills. According to muscle analogy (Baumeister et al., 2007), psychological skills may even decrease when not in use. Overprotection could therefore be another problem in developing psychological skills, as it may prevent challenges from occurring and skills from being trained. Overall, it seems necessary to balance some external variables (e.g., competitive demands) so that they are challenging enough to trigger the practice of psychological skills (e.g., anxiety-control skills) but not too challenging to avoid psychological distress (e.g., depression).

\section{Applied SEP Practice}

Applied SEP practice has played a central role in this scientific field since the inception of SEP (Singer, 1976). It is therefore only logical that applied SEP practice in the knowledge map occupied a predominant position. Based on the SEP literature, field work of applied practitioners can be divided into strategic actions, targeted interventions, and therapeutic frameworks.

Strategic actions may be seen as the active ingredients in service delivery of sport and exercise psychologists (Tod et al., 2019). Examples of strategic actions reported in research include integrating into a team's internal culture, displaying good listening skills, understanding the reality that clients face, and encouraging clients to feel safe to disclose their problems (FortinGuichard et al., 2018). Targeted interventions, which include diverse strategic actions, address specific problems in sport and exercise, such as coach behavior (e.g., coach development programs, Evans et al., 2015), endurance performance (e.g., music interventions, Karageorghis and Priest, 2012), skill acquisition (e.g., mental simulation practice, Moran et al., 2012), resilience (e.g., resilience-building programs, Galli and Gonzalez, 2015), attention and motivation (e.g., strategic self-talk interventions, Hatzigeorgiadis et al., 2011), or psychological skills (e.g., psychological skills training, Birrer and Morgan, 2010).

Lastly, therapeutic frameworks, which include a wide variety of strategic actions and sometimes even targeted interventions, partly define practitioners' professional philosophy, that is, the beliefs and values that guide practitioners in their work (Fortin-Guichard et al., 2018; Poczwardowski, 2019). Concepts that refer to therapeutic frameworks and professional philosophy explored in SEP research include Rational-Emotive Behavior Therapy (Jordana et al., 2020), Cognitive Behavioral Therapy (Puig and Pummel, 2012), Motivational Interviewing (Akinrolie et al., 2020), and Mindfulness-Acceptance-Commitment approaches (Moore, 2009; see also, Poczwardowski et al., 2004). By examining strategic actions, targeted interventions, and therapeutic frameworks, researchers in SEP have mainly applied psychology knowledge and practice to improve sport and exercise experiences. However, the ultimate purpose of SEP is not focused exclusively on sport and exercise experiences, as the field also aims to have positive effects beyond sport and exercise for individuals, collectives, and societies.

Accordingly, the context and practice of sports and exercise also provide a therapeutic framework to promote, among others, positive youth development (Holt et al., 2017), physical health (Demetriou and Höner, 2012), mental health (Morres et al., 2019), and social interactions (Shvedko et al., 2018). Research has shown that sport and exercise practice can benefit a wide range of external variables, biopsychological descriptors, and psychological skills. For example, sport and exercise participation involves a social context and characteristic tasks that are 
important, in mental health, working memory, or social skills (Moreau and Conway, 2013). Sports and exercise practice can also elicit pleasant and challenging experiences, positive social interactions, and feelings of success and competence (Gayman et al., 2017). Moreover, participation in sport can enhance problem-solving and communication skills among young people (Holt et al., 2017). Overall, it is a remarkable feature that in SEP practice sports and exercise to are used to influence life development, as well as psychological knowledge and procedures are applied to enhance athletic experiences.

\section{Section Summary}

It is important to consider SEP not just as a psychological science in the service of sports and exercise experiences and performance. Sports and exercise can equally be used as a therapeutic framework for some of the social, development, health, and well-being challenges (e.g., Smith et al., 2019) that psychologists attempt to solve in other psychological disciplines. Furthermore, any psychological intervention, including sport and exercise practice, can be effective by targeting individual or combined aspects of biopsychological descriptors, external variables, and psychological skills.

In the future, researchers might want to differentiate between two potentially overlapping groups of interventions: (a) those based on changing external variables (e.g., working with athletes' parents and coaches) and biopsychological descriptors (e.g., establishing goals for athletes) to benefit how people are, who they are, and their impact on external variables (e.g., emotions

TABLE 1 | Suggestions of how the knowledge map can help teach sport and exercise psychology (SEP), establish interdisciplinary research, and to further develop the field.

Three suggestions for teaching SEP to students

Three suggestions for interdisciplinary research

Three suggestions for SEP experts
(1) The knowledge map introduces SEP as a science that studies the network of biopsychological descriptors, external variables, and psychological skills, and develops practices to improve that network, to improve sports and exercise experiences, and to promote positive life development thought sport and exercise.

(2) Teachers can create a glossary of concepts that will appear during a SEP module and ask students to put them on the knowledge map and examine the relationships between these concepts based on previous knowledge and personal experience.

(3) Students writing their dissertation on a SEP topic can put their topic of interest on the knowledge map and examine related concepts in different clusters to find potentially innovative research questions.

(1) The knowledge map shows that SEP researchers and experts from other psychological disciplines and related sciences are interested in similar concepts. Understanding SEP research will contribute to the cross-pollination of findings between fields, thereby promoting the growth of interdisciplinary research.

(2) SEP researchers have used sports and exercise tasks to manipulate similar variables that other experts in psychology and related sciences want to study. These tasks could have greater ecological validity than laboratory tasks and be therefore attractive as a research paradigm.

(3) In SEP, sports and exercise programs have proven beneficial for individual and collective conditions, which experts from all psychological and related sciences aim at in research and practice.

(1) In order to examine individual and collective psychological realities, the knowledge map can help select a more holistic set of variables for interviews, field observations, objective measures, and questionnaires.

(2) To set up a study, relevant variables are placed into clusters and subclusters. Difficulty deciding between two or more clusters could indicate that variables in general or in the context of the study are not well enough defined.

(3) To systematically review one specific topic, the topic could be placed on the map next to other concepts that appear in its nomological network.
E.g., Students can learn that SEP describes athletes by attributes and processes such as personality and emotions that are influenced by external variables such as spectators and that may need to be adjusted by psychological skills such as anger control. SEP practitioners would help athletes to get the most out of sports practice or to use sports for their personal benefit, for example to acquire life skills.

E.g., During a SEP module, students study task difficulty, effort, and concentration. With their teacher, students place tasks in external variables, effort in descriptors, and concentration in skills. Students discus that a lack of focus can lead to less effort, making tasks harder, or that difficult tasks that require more effort make it harder to concentrate.

E.g., A Ph.D. student is interested in sports anxiety. Guided by the knowledge map, they thought about studying its relation to the descriptor sports identity, the external sports culture, and self-acceptance skills.

E.g., Self-talk is studied in SEP as well as in other psychological disciplines and related sciences. While SEP experts develop self-talk interventions, developmental psychologists study the role of self-talk in internalizing self-regulatory processes, and educational researchers explore how self-talk facilitates mastery motivation. Yet, a lack of cross-referencing hampers the interdisciplinary development of the self-talk area.

E.g., To study concentration and performance, researchers have used tasks like the sustained attention reaction task to control for example time, difficulty, and criteria for success. In sports tasks with potentially greater ecological validity, like golf puts or tennis returns, similar parameters can be controlled.

E.g., Aerobic exercise in 45-min sessions at moderate intensity three times a week has a significantly large overall antidepressant effect in adults with a clinical diagnosis of major depression.

E.g., To examine an athletes' psychological reality, a practitioner could consider observing external variables (e.g., parental behavior), measuring biopsychological descriptors (e.g., muscular tension), and asking about psychological skills (e.g., imagery).

E.g., In a study about the relations between instructor style, exercise motivation, and commitment, authors could notice that instructor style may be an external variable or a perception, motivation could be a contextual attribute or a situational process, and commitment could be an automatic descriptor or an effortful skill.

E.g., Prosocial and antisocial behavior were predicted by external variables like motivational climate and coach behavior, biopsychological descriptors like social identity and intrinsic motivation, and psychological skills like moral disengagement. 
and emotion expression); and (b) those striving to fortify people's psychological skills (e.g., emotion control skills) so that people better self-regulate their biopsychological descriptors (e.g., frustration) and positively influence their environment (e.g., through positive emotion expression). If future research further clarifies the differences and overlaps between these two groups of interventions, applied practitioners could make more explicit decisions as to whether they aim to improve individual and collective psychological skills (e.g., in talent development), or whether the situation requires them to be more directly responsible for positive sports and exercise experiences (e.g., for acute problems).

\section{DISCUSSION}

In the previous sections, research on psychological aspects related to sport and exercise was summarized in a knowledge map of SEP. The current section briefly discusses key insights gained from the synthesis of the SEP literature. This is mainly a possible answer to the question of what SEP is today. Based on relevant research topics, a conceptualization of SEP has emerged from the present work.

\section{The Conceptualization of SEP}

In relation to SEP research topics, the present integrative perspective provides guidance to formulate a comprehensive conceptualization of the field. Essentially, SEP can be divided into two broad connected areas: one that investigates the dynamic relationship between biopsychological descriptors, external variables, and psychological skills; and another that looks at applied SEP practice that aims to improve that relationship. Regarding the first area, research has focused on both personal and interpersonal aspects of biopsychological descriptors and psychological skills. Regarding the second area, applied SEP practice is developed to meet two grand objectives: to improve athletic experiences (i.e., performance, social behavior, and general participant satisfaction); and to promote positive life development (i.e., life skills, socialization, physical and mental health, and general wellbeing, Schinke et al., 2016; even existential learning, Ronkainen et al., 2020) through strategic sport and exercise practice.

So, what would SEP be, considering the above aspects? SEP can be described as the science that (a) explores the dynamic network of biopsychological descriptors, external variables, and psychological skills that determine sport and exercise experiences, and (b) examines applied SEP practice that deals with different parts of this network in order to improve sport and exercise experiences and to promote positive life development through sport and exercise.

\section{CLOSING REMARKS}

This integrative perspective on the SEP research landscape was elaborated to answer what SEP is and what it is about. The knowledge map of SEP developed here provides a global synthesis of a scientific area that transcends disciplinary boundaries. The present knowledge map is the result of a multidisciplinary approach that included studies published in SEP as well as in other psychological sciences (Srismith et al., 2020), sports sciences (Hanlon et al., 2019), education (Casey and Quennerstedt, 2020), sociology (Valiente, 2019), health sciences (Gillison et al., 2019), physiology (Brick et al., 2016), and medicine (Bogardus et al., 2019), among others.

The present work presents a personal perspective of SEP. The perspective developed through reading, informal conversations, and free thought association during mindwandering. In terms of its true value, since this work presents perspectives intended to inspire new ideas and advancements related to SEP, it should be valued less for its accuracy than for its potential impact. The intended impact of this project was to positively influence the teaching of the SEP, to promote interdisciplinary research, and practice and to support the development of the scientific SEP area. Table 1 contains three suggestions for each of the above sub-goals and illustrative examples. The knowledge map can be useful to introduce SEP as a subject area, to present module content, and to support students in creating research questions. For researchers from other psychological disciplines and related scientific areas, the knowledge map shows common research interests, the potential of sport and exercise as ecologically valid experimental tasks, and sport and exercise as a therapeutic framework for interdisciplinary use. For SEP experts, the knowledge map can be used to examine psychological realities in applied practice (e.g., using \#SportPsychMapping; Latinjak et al., in press), represent nomological networks of SEP concepts, and test the specificity of conceptualizations of research variables. To conclude, today SEP is not just a subdiscipline of psychology or sport sciences; rather, SEP would be a scientific interdisciplinary hub where interest in people's psychological experiences converges with a psychologically, sociologically, educationally, biologically, economically, and even philosophically interesting context: sport and exercise.

\section{AUTHOR CONTRIBUTIONS}

$\mathrm{AL}$ has prepared the first version of the knowledge map. $\mathrm{AH}$ and $\mathrm{AL}$ jointly developed the manuscript in its current form. Both authors contributed to the article and approved the submitted version.

\section{FUNDING}

This work was supported by the University of Suffolk and the University of Thessaly.

\section{SUPPLEMENTARY MATERIAL}

The Supplementary Material for this article can be found online at: https://www.frontiersin.org/articles/10.3389/fpsyg.2021. 661824/full\#supplementary-material 


\section{REFERENCES}

Akinrolie, O., Barclay, R., Strachan, S., Gupta, A., Jasper, U. S., Jumbo, S. U., et al. (2020). The effect of motivational interviewing on physical activity level among older adults: a systematic review and meta-analysis. Phys. Occup. Ther. Geriatr. 38, 250-263. doi: 10.1080/02703181.2020.1725217

Araújo, D., Hristovski, R., Seifert, L., Carvalho, J., and Davids, K. (2019). Ecological cognition: expert decision-making behaviour in sport. Int. Rev. Sport Exerc. Psychol. 12, 1-25. doi: 10.1080/1750984X.2017.1349826

Arnold, R., and Fletcher, D. (2012). A research synthesis and taxonomic classification of the organizational stressors encountered by sport performers. J. Sport Exerc. Psychol. 34, 397-429. doi: 10.1123/jsep.34.3.397

Audiffren, M., and André, N. (2015). The strength model of self-control revisited: linking acute and chronic effects of exercise on executive functions. J. Sport Health Sci. 4, 30-46. doi: 10.1016/j.jshs.2014.09.002

Baker, J., Wilson, S., Johnston, K., Dehghansai, N., Koenigsberg, A., De Vegt, S., et al. (2020). Talent Research in Sport 1990-2018: a Scoping Review. Front. Psychol. 11:607710. doi: 10.3389/fpsyg.2020.607710

Balish, S. M., Eys, M. A., and Schulte-Hostedde, A. I. (2013). Evolutionary sport and exercise psychology: integrating proximate and ultimate explanations. Psychol. Sport Exerc. 14, 413-422. doi: 10.1016/j.psychsport.2012.12.006

Balish, S. M., McLaren, C., Rainham, D., and Blanchard, C. (2014). Correlates of youth sport attrition: a review and future directions. Psychol. Sport Exerc. 15, 429-439. doi: 10.1016/j.psychsport.2014.04.003

Bányai, F., Griffiths, M. D., Király, O., and Demetrovics, Z. (2019). The psychology of esports: a systematic literature review. J. Gambl. Stud. 35, 351-365. doi: 10.1007/s10899-018-9763-1

Bar, R. J., Cassin, S. E., and Dionne, M. M. (2016). Eating disorder prevention initiatives for athletes: a review. Eur. J. Sport Sci. 16, 325-335. doi: 10.1080/ 17461391.2015.1013995

Barcia, A. M., Shaha, J. S., and Tokish, J. M. (2019). The resilient athlete: lessons learned in the military. Sports Med. Arthrosc. Rev. 27, 124-128. doi: 10.1097/ JSA.0000000000000234

Baumeister, R. F., Vohs, K. D., and Tice, D. M. (2007). The strength model of self-control. Curr. Dir. Psychol. Sci. 16, 351-355.

Beauchamp, M. R., Maclachlan, A., and Lothian, A. M. (2005). Communication within sport teams: jungian preferences and group dynamics. Sport Psychol. 19, 203-220. doi: 10.1123/tsp.19.2.203

Bevan, W. (1991). Contemporary psychology: a tour inside the onion. Am. Psychol. 46, 475-483. doi: 10.1037/0003-066X.46.5.475

Biddle, S. (1997). Current trends in sport and exercise psychology research. Psychol. Bull. Br. Psychol. Soc. 10, 63-69.

Biddle, S. J., and Fuchs, R. (2009). Exercise psychology: a view from Europe. Psychol. Sport Exerc. 10, 410-419. doi: 10.1016/j.psychsport.2009.02.011

Birrer, D., and Morgan, G. (2010). Psychological skills training as a way to enhance an athlete's performance in high-intensity sports. Scand. J. Med. Sci. Sports 20, 78-87. doi: 10.1111/j.1600-0838.2010.01188.x

Bogardus, R. L., Martin, R. J., Richman, A. R., and Kulas, A. S. (2019). Applying the Socio-Ecological Model to barriers to implementation of ACL injury prevention programs: a systematic review. J. Sport Health Sci. 8, 8-16. doi: 10.1016/j.jshs. 2017.11.001

Bortoli, L., Bertollo, M., Hanin, Y., and Robazza, C. (2012). Striving for excellence: a multi-action plan intervention model for shooters. Psychol. Sport Exerc. 13, 693-701. doi: 10.1016/j.psychsport.2012.04.006

Brick, N. E., MacIntyre, T. E., and Campbell, M. J. (2016). Thinking and action: a cognitive perspective on self-regulation during endurance performance. Front. Physiol. 7:159. doi: 10.3389/fphys.2016.00159

Browne, M. A., and Mahoney, M. J. (1984). Sport psychology. Annu. Rev. Psychol. 35, 605-625. doi: 10.1146/annurev.ps.35.020184.003133

Campo, M., Mackie, D. M., and Sanchez, X. (2019). Emotions in group sports: a narrative review from a social identity perspective. Front. Psychol. 10:666. doi: 10.3389/fpsyg.2019.00666

Carson, H. J., and Collins, D. (2016). The fourth dimension: a motoric perspective on the anxiety-performance relationship. Int. Rev. Sport Exerc. Psychol. 9, 1-21. doi: 10.1080/1750984X.2015.1072231

Casey, A., and Quennerstedt, M. (2020). Cooperative learning in physical education encountering Dewey's educational theory. Eur. Phys. Educ. Rev. 26, 1023-1037.
Chen, X., Holland, P., and Galea, J. M. (2018). The effects of reward and punishment on motor skill learning. Curr. Opin. Behav. Sci. 20, 83-88. doi: 10.1016/j.cobeha.2017.11.011

Chen, Y., Buggy, C., and Kelly, S. (2019). Winning at all costs: a review of risktaking behaviour and sporting injury from an occupational safety and health perspective. Sports Med. Open 5:15. doi: 10.1186/s40798-019-0189-9

Chuckravanen, D., Bulut, S., Kürklü, G. B., and Yapali, G. (2019). Review of exercise-induced physiological control models to explain the development of fatigue to improve sports performance and future trend. Sci. Sports 34, 131-140. doi: 10.1016/j.scispo.2018.10.017

Clancy, R. B., Herring, M. P., and Campbell, M. J. (2017). Motivation measures in sport: a critical review and bibliometric analysis. Front. Psychol. 8:348. doi: 10.3389/fpsyg.2017.00348

Cooke, A. (2013). Readying the head and steadying the heart: a review of cortical and cardiac studies of preparation for action in sport. Int. Rev. Sport Exerc. Psychol. 6, 122-138. doi: 10.1080/1750984X.2012.724438

Cooper, J. N., Macaulay, C., and Rodriguez, S. H. (2019). Race and resistance: a typology of African American sport activism. Int. Rev. Sociol. Sport 54, $151-181$.

Cotterill, S. T., and Fransen, K. (2016). Athlete leadership in sport teams: current understanding and future directions. Int. Rev. Sport Exerc. Psychol. 9, 116-133. doi: 10.1080/1750984X.2015.1124443

Cross, E. S., Acquah, D., and Ramsey, R. (2014). A review and critical analysis of how cognitive neuroscientific investigations using dance can contribute to sport psychology. Int. Rev. Sport Exerc. Psychol. 7, 42-71. doi: 10.1080/1750984X. 2013.862564

Demetriou, Y., and Höner, O. (2012). Physical activity interventions in the school setting: a systematic review. Psychol. Sport Exerc. 13, 186-196. doi: 10.1016/j. psychsport.2011.11.006

Derevensky, J. L., McDuff, D., Reardon, C. L., Hainline, B., Hitchcock, M. E., and Richard, J. (2019). Problem gambling and associated mental health concerns in elite athletes: a narrative review. Br. J. Sports Med. 53, 761-766. doi: 10.1136/ bjsports-2019-100668

Dohme, L. C., Backhouse, S., Piggott, D., and Morgan, G. (2017). Categorising and defining popular psychological terms used within the youth athlete talent development literature: a systematic review. Int. Rev. Sport Exerc. Psychol. 10, 134-163. doi: 10.1080/1750984X.2016.1185451

Eklund, R. C., and Crocker, P. R. E. (2019). "The nature of sport, exercise, and physical activity psychology," in Advances In Sport And Exercise Psychology, Fourth Edition, eds T. S. Horn and A. L. Smith (Champaign Il: Human Kinetics), $4-14$.

Elbe, A. M., Bertollo, M., Debois, N., De Oliveira, R., Fritsch, J., Hatzigeorgiadis, A., et al. (2019). Preface to the special issue: 50 years of FEPSAC. Psychol. Sport Exerc. 42, 5-7. doi: 10.1016/j.psychsport.2018.09.009

Englert, C., Graham, J. D., and Bray, S. R. (2020). Self-control in sport and exercise psychology. Sport Exerc. Perform. Psychol. 9, 161-166. doi: 10.1037/spy0000205

Evans, M. B., McGuckin, M., Gainforth, H. L., Bruner, M. W., and Côté, J. (2015). Coach development programmes to improve interpersonal coach behaviours: a systematic review using the re-aim framework. Br. J. Sports Med. 49, 871-877. doi: 10.1136/bjsports-2016-096725

Fortin-Guichard, D., Boudreault, V., Gagnon, S., and Trottier, C. (2018). Experience, effectiveness, and perceptions toward sport psychology consultants: a critical review of peer-reviewed articles. J. Appl. Sport Psychol. 30, 3-22. doi: 10.1080/10413200.2017.1318416

Friesen, A. P., Lane, A. M., Devonport, T. J., Sellars, C. N., Stanley, D. N., and Beedie, C. J. (2013). Emotion in sport: considering interpersonal regulation strategies. Int. Rev. Sport Exerc. Psychol. 6, 139-154. doi: 10.1080/1750984X. 2012.742921

Furley, P. (2019). What modern sports competitions can tell us about human nature. Perspect. Psychol. Sci. 14, 138-155.

Furley, P., Schweizer, G., and Bertrams, A. (2015). The two modes of an athlete: dual-process theories in the field of sport. Int. Rev. Sport Exerc. Psychol. 8, 106-124. doi: 10.1080/1750984X.2015.1022203

Galli, N., and Gonzalez, S. P. (2015). Psychological resilience in sport: a review of the literature and implications for research and practice. Int. J. Sport Exerci. Psychol. 13, 243-257. doi: 10.1080/1612197X.2014.946947

Gayman, A. M., Fraser-Thomas, J., Dionigi, R. A., Horton, S., and Baker, J. (2017). Is sport good for older adults? A systematic review of psychosocial outcomes 
of older adults' sport participation. Int. Rev. Sport Exerc. Psychol. 10, 164-185. doi: 10.1080/1750984X.2016.1199046

Gillison, F. B., Rouse, P., Standage, M., Sebire, S. J., and Ryan, R. M. (2019). A meta-analysis of techniques to promote motivation for health behaviour change from a self-determination theory perspective. Health Psychol. Rev. 13, 110-130. doi: 10.1080/17437199.2018.1534071

Glazier, P. S. (2017). Towards a grand unified theory of sports performance. Hum. Mov. Sci. 56, 139-156. doi: 10.1016/j.humov.2015.08.001

Gucciardi, D. F., Hanton, S., and Fleming, S. (2017). Are mental toughness and mental health contradictory concepts in elite sport? A narrative review of theory and evidence. J. Sci. Med. Sport 20, 307-311. doi: 10.1016/j.jsams.2016.08.006

Gustafsson, H., Hancock, D. J., and Côté, J. (2014). Describing citation structures in sport burnout literature: a citation network analysis. Psychol. Sport Exerc. 15, 620-626. doi: 10.1016/j.psychsport.2014.07.001

Hagger, M. S. (2019). Habit and physical activity: theoretical advances, practical implications, and agenda for future research. Psychol. Sport Exerc. 42, 118-129. doi: 10.1016/j.psychsport.2018.12.007

Hanlon, C., Jenkin, C., and Craike, M. (2019). Associations between environmental attributes of facilities and female participation in sport: a systematic review. Manag. Sport Leis. 24, 294-306. doi: 10.1080/23750472.2019.1641138

Harwood, C. G., Keegan, R. J., Smith, J. M., and Raine, A. S. (2015). A systematic review of the intrapersonal correlates of motivational climate perceptions in sport and physical activity. Psychol. Sport Exerc. 18, 9-25. doi: 10.1016/j. psychsport.2014.11.005

Hatzigeorgiadis, A., Zourbanos, N., Galanis, E., and Theodorakis, Y. (2011). Selftalk and sports performance: a meta-analysis. Perspect. Psychol. Sci. 6, 348-356.

Holt, N. L., Neely, K. C., Slater, L. G., Camiré, M., Côté, J., Fraser-Thomas, J., et al. (2017). A grounded theory of positive youth development through sport based on results from a qualitative meta-study. Int. Rev. Sport Exerc. Psychol. 10, 1-49. doi: 10.1080/1750984X.2016.1180704

Jackson, B., Dimmock, J., and Compton, J. (2020). Persuasion And Communication In Sport, Exercise, And Physical Activity. London: Routledge.

Jason, T., McGannon, K. R., Blanchard, C. M., Rainham, D., and Dechman, G. (2015). A systematic gender-based review of physical activity correlates in coronary heart disease patients. Int. Rev. Sport Exerc. Psychol. 8, 1-23. doi: 10.1080/1750984X.2014.932425

Jordana, A., Turner, M., Ramis, Y., and Torregrossa, M. (2020). A systematic mapping review on the use of Rational Emotive Behavior Therapy (REBT) with athletes. Int. Rev. Sport Exerc. Psychol. doi: 10.1080/1750984X.2020.1836673

Karageorghis, C. I., and Priest, D. L. (2012). Music in the exercise domain: a review and synthesis (Part I). Int. Rev. Sport Exerc. Psychol. 5, 44-66. doi: 10.1080/1750984X.2011.631026

Kavoura, A., and Kokkonen, M. (2020). What do we know about the sporting experiences of gender and sexual minority athletes and coaches? A scoping review. Int. Rev. Sport Exerc. Psychol. 2020, 1-27.

Kavussanu, M., and Al-Yaaribi, A. (2019). Prosocial and antisocial behaviour in sport. Int. J. Sport Exerc. Psychol. 19, 179-202.

Kendellen, K., and Camiré, M. (2019). Applying in life the skills learned in sport: a grounded theory. Psychol. Sport Exerc. 40, 23-32. doi: 10.1016/j.psychsport. 2018.09.002

Kent, S., Devonport, T. J., Lane, A. M., Nicholls, W., and Friesen, A. P. (2018). The effects of coping interventions on ability to perform under pressure. J. Sports Sci. Med. 17:40.

Kumari, N., Taylor, D., and Signal, N. (2019). The effect of cerebellar transcranial direct current stimulation on motor learning: a systematic review of randomized controlled trials. Front. Hum. Neurosci. 13:328. doi: 10.3389/ fnhum.2019.00328

Laborde, S., Mosley, E., and Ueberholz, L. (2018). Enhancing cardiac vagal activity: factors of interest for sport psychology. Prog. Brain Res. 240, 71-92. doi: 10. 1016/bs.pbr.2018.09.002

Latinjak, A. T., Hatzigeorgiadis, A., Comoutos, N., and Hardy, J. (2019). Speaking clearly ...10 years on: the case for an integrative perspective of self-talk in sport. Sport Exerc. Perform. Psychol. 8, 353-367. doi: 10.1037/spy00 00160

Latinjak, A. T., Morelló-Tomás, E., and Figal-Gómez, L. (in press). \#SportPsychMapping: an exploratory interview framework for sport and exercise psychology. Sport Psychol. doi: 10.1123/tsp.20200120
Liew, G., Kuan, G., Chin, N., and Hairul, A. H. (2019). Mental toughness in sport: systematic review and future. German J. Exerc. Sport Res. 49, 381-394. doi: 10.1007/s12662-019-00603-3

Lindahl, J., Stenling, A., Lindwall, M., and Colliander, C. (2015). Trends and knowledge base in sport and exercise psychology research: a bibliometric review study. Int. Rev. Sport Exerc. Psychol. 8, 71-94. doi: 10.1080/1750984X.2015. 1019540

MacIntyre, T. E., Igou, E. R., Campbell, M. J., Moran, A. P., and Matthews, J. (2014). Metacognition and action: a new pathway to understanding social and cognitive aspects of expertise in sport. Front. Psychol. 5:1155. doi: 10.3389/fpsyg.2014. 01155

Mareš, L. (2019). Practical role of philosophy in sport: case of philosophical consultation. Phys. Cult. Sport Stud. Res. 83, 16-25. doi: 10.2478/pcssr-20190017

Massey, W. V., Meyer, B. B., and Naylor, A. H. (2013). Toward a grounded theory of self-regulation in mixed martial arts. Psychol. Sport Exerc. 14, 12-20. doi: 10.1016/j.psychsport.2012.06.008

Meijen, C., Turner, M., Jones, M. V., Sheffield, D., and McCarthy, P. (2020). A theory of challenge and threat states in athletes: a revised conceptualization. Front. Psychol. 11:126. doi: 10.3389/fpsyg.2020.00126

Melnikoff, D. E., and Bargh, J. A. (2018). The mythical number two. Trends Cogn. Sci. 22, 280-293. doi: 10.1016/j.tics.2018.02.001

Moore, Z. E. (2009). Theoretical and empirical developments of the MindfulnessAcceptance-Commitment (MAC) approach to performance enhancement. J. Clin. Sport Psychol. 3, 291-302. doi: 10.1123/jcsp.3.4.291

Moore, Z. E., and Bonagura, K. (2017). Current opinion in clinical sport psychology: from athletic performance to psychological well-being. Curr. Opin. Psychol. 16, 176-179. doi: 10.1016/j.copsyc.2017.05.016

Moran, A. (2012). "Concentration: attention and performance," in The Oxford Handbook of Sport and Performance Psychology, ed. S. Murphy (Oxford: Oxford University Press), 117-130.

Moran, A., Guillot, A., MacIntyre, T., and Collet, C. (2012). Re-imagining motor imagery: building bridges between cognitive neuroscience and sport psychology. Br. J. Psychol. 103, 224-247. doi: 10.1111/j.2044-8295.2011. 02068.x

Moreau, D., and Conway, A. R. (2013). Cognitive enhancement: a comparative review of computerized and athletic training programs. Int. Rev. Sport Exerc. Psychol. 6, 155-183. doi: 10.1080/1750984X.2012. 758763

Morente-Sánchez, J., and Zabala, M. (2013). Doping in sport: a review of elite athletes' attitudes, beliefs, and knowledge. Sports Med. 43, 395-411. doi: 10. 1007/s40279-013-0037-x

Morres, I. D., Hatzigeorgiadis, A., Stathi, A., Comoutos, N., Arpin-Cribbie, C., Krommidas, C., et al. (2019). Aerobic exercise for adult patients with major depressive disorder in mental health services: a systematic review and metaanalysis. Depress. Anxiety 36, 39-53. doi: 10.1002/da.22842

Neimeyer, G. J., Taylor, J. M., and Rozensky, R. H. (2012). The diminishing durability of knowledge in professional psychology: a Delphi Poll of specialties and proficiencies. Prof. Psychol. Res. Pr. 43, 364-371. doi: 10.1037/ a0028698

Németh, L., De la Vega, R., and Szabo, A. (2016). Research in Sport and Exercise Psychology between 2003 and 2013: an analysis of the English-speaking publication trends before the field's 50th anniversary. Revista de Psicología del Deporte 25, 157-165.

Ng, J. Y. Y., Ntoumanis, N., Thogersen-Ntoumani, E. C., Deci, E. L., Ryan, R. M., Duda, J. L., et al. (2012). Self-Determination Theory applied to health contexts: a meta-analysis. Perspect. Psychol. Sci. 7, 325-340.

Norris, L. A., Didymus, F. F., and Kaiseler, M. (2017). Stressors, coping, and wellbeing among sports coaches: a systematic review. Psychol. Sport Exerc. 33, 93-112. doi: 10.1016/j.psychsport.2017.08.005

Ntoumanis, N., Ng, J. Y. Y., Barkoukis, V., and Backhouse, S. (2014). Personal and situational predictors of doping use in physical activity settings: a meta-analysis. Sports Med. 44, 1603-1624. doi: 10.1007/s40279-014-0240-4

Ometto, L., Vasconcellos, F. V., Cunha, F. A., Teoldo, I., Souza, C. R. B., Dutra, M. B., et al. (2018). How manipulating task constraints in small-sided and conditioned games shapes emergence of individual and collective tactical behaviours in football: a systematic review. Int. J. Sports Sci. Coach. 13, 12001214 . 
Ong, N. C. H. (2015). The use of the Vienna Test System in sport psychology research: a review. Int. Rev. Sport Exerc. Psychol. 8, 204-223. doi: 10.1080/ 1750984X.2015.1061581

Pageaux, B. (2016). Perception of effort in exercise science: definition, measurement and perspectives. Eur. J. Sport Sci. 16, 885-894. doi: 10.1080/ 17461391.2016.1188992

Paulus, M. P., Potterat, E. G., Taylor, M. K., Van Orden, K. F., Bauman, J., Momen, N., et al. (2009). A neuroscience approach to optimizing brain resources for human performance in extreme environments. Neurosci. Biobehav. Rev. 33, 1080-1088. doi: 10.1016/j.neubiorev.2009.05.003

Poczwardowski, A. (2019). Deconstructing sport and performance psychology consultant: expert, person, performer, and self-regulator. Int. J. Sport Exerc. Psychol. 17, 427-444. doi: 10.1080/1612197X.2017.1390484

Poczwardowski, A., Sherman, C. P., and Ravizza, K. (2004). Professional philosophy in the sport psychology service delivery: building on theory and practice. Sport Psychol. 18, 445-463. doi: 10.1123/tsp.18.4.445

Portenga, S. T., Aoyagi, M. W., and Cohen, A. B. (2017). Helping to build a profession: a working definition of sport and performance psychology. J. Sport Psychol. Action 8, 47-59. doi: 10.1080/21520704.2016.1227413

Puig, J., and Pummel, B. (2012). 'I can't lose this match!': cognitive behaviour therapy and the sport psychologist. Sport Exerc. Psychol. Rev. 8, 54-64.

Raab, M. (2017). Sport and exercise psychology in 2050. German J. Exerc. Sport Res. 47, 62-71. doi: 10.1007/s12662-016-0435-y

Reeve, J. (2009). Why teachers adopt a controlling motivating style toward students and how they can become more autonomy supportive. Educ. Psychol. 44, 159-175. doi: 10.1080/00461520903028990

Renshaw, I., Davids, K., Araújo, D., Lucas, A., Roberts, W. M., Newcombe, D. J., et al. (2019). Evaluating weaknesses of "perceptual-cognitive training" and "brain training" methods in sport: an ecological dynamics critique. Front. Psychol. 9:2468. doi: 10.3389/fpsyg.2018.02468

Rhodes, R. E., and Nasuti, G. (2011). Trends and changes in research on the psychology of physical activity across 20 years: a quantitative analysis of 10 journals. Prev. Med. 53, 17-23. doi: 10.1016/j.ypmed.2011.06.002

Roberts, V., Sojo, V., and Grant, F. (2019). Organisational factors and nonaccidental violence in sport: a systematic review. Sport Manag. Rev. 23, 8-27. doi: 10.1016/j.smr.2019.03.001

Ronkainen, N. J., Aggerholm, K., Ryba, T. V., and Allen-Collinson, J. (2020). Learning in sport: from life skills to existential learning. Sport Educ. Soc. 26, 214-227.

Ryba, T. V. (2017). Cultural sport psychology: a critical review of empirical advances. Curr. Opin. Psychol. 16, 123-127. doi: 10.1016/j.copsyc.2017.05.003

Sarkar, M., and Fletcher, D. (2014). Psychological resilience in sport performers: a review of stressors and protective factors. J. Sports Sci. 32, 1419-1434. doi: 10.1080/02640414.2014.901551

Scheffer, M., Baas, M., and Bjordam, T. K. (2017). Teaching originality? Common habits behind creative production in science and arts. Ecol. Soc. 22:29.

Scheffer, M., Bascompte, J., Bjordam, T. K., Carpenter, S. R., Clarke, L. B., Folke, C., et al. (2015). Dual thinking for scientists. Ecol. Soc. 20:3.

Schinke, R. J., Stambulova, N. R., Lidor, R., Papaioannou, A., and Ryba, T. V. (2016). ISSP position stand: social missions through sport and exercise psychology. Int. J. Sport Exerc. Psychol. 14, 4-22. doi: 10.1080/1612197X.2014. 999698

Sheridan, D., Coffee, P., and Lavallee, D. (2014). A systematic review of social support in youth sport. Int. Rev. Sport Exerc. Psychol. 7, 198-228. doi: 10.1080/ 1750984X.2014.931999

Shoenfelt, E. L. (2016). How much do we really know about employee resilience? More, if we include the sport psychology resilience research. Ind. Organ. Psychol. 9, 442-446. doi: 10.1017/iop.2016.36

Shvedko, A., Whittaker, A. C., Thompson, J. L., and Greig, C. A. (2018). Physical activity interventions for treatment of social isolation, loneliness or low social support in older adults: a systematic review and meta-analysis of randomised controlled trials. Psychol. Sport Exerc. 34, 128-137. doi: 10.1016/j.psychsport. 2017.10.003

Singer, R. N. (1976). Sport Psychology. J. Phys. Educ. Recreat. 47, 24-25. doi: 10.1080/00971170.1976.10617527
Smith, N., Quested, E., Appleton, P. R., and Duda, J. L. (2016). A review of observational instruments to assess the motivational environment in sport and physical education settings. Int. Rev. Sport Exerc. Psychol. 9, 134-159. doi: 10.1080/1750984X.2015.1132334

Smith, R., Spaaij, R., and McDonald, B. (2019). Migrant integration and cultural capital in the context of sport and physical activity: a systematic review. J. Int. Migr. Integr. 20, 851-868. doi: 10.1007/s12134-018-0634-5

Sparkes, A. C., and Smith, B. (2009). Judging the quality of qualitative inquiry: criteriology and relativism in action. Psychol. Sport Exerc. 10, 491-497. doi: 10.1016/j.psychsport.2009.02.006

Srismith, D., Wider, L. M., Wong, H. Y., Zipfel, S., Thiel, A., Giel, K. E., et al. (2020). Influence of physical activity interventions on body representation: a systematic review. Front. Psychiatry 11:99. doi: 10.3389/fpsyt.2020.00099

Stambulova, N. B., and Wylleman, P. (2019). Psychology of athletes' dual careers: a state-of-the-art critical review of the European discourse. Psychol. Sport Exerc. 42, 74-88. doi: 10.1016/j.psychsport.2018.11.013

Stevens, C. J., Mauger, A. R., Hassmèn, P., and Taylor, L. (2018). Endurance performance is influenced by perceptions of pain and temperature: theory, applications and safety considerations. Sports Med. 48, 525-537. doi: 10.1007/ s40279-017-0852-6

Strain, T., Milton, K., Dall, P., Standage, M., and Mutrie, N. (2019). How are we measuring physical activity and sedentary behaviour in the four home nations of the UK? A narrative review of current surveillance measures and future directions. Br. J. Sports Med. 54:bjsports-2018-100355.

Swann, C., Piggott, D., Schweickle, M., and Vella, S. A. (2018). A review of scientific progress in flow in sport and exercise: normal science, crisis, and a progressive shift. J. Appl. Sport Psychol. 30, 249-271. doi: 10.1080/10413200.2018.1443525

Tod, D., Hardy, J., Lavallee, D., Eubank, M., and Ronkainen, N. (2019). Practitioners' narratives regarding active ingredients in service delivery: collaboration-based problem solving. Psychol. Sport Exerc. 43, 350-358. doi: 10.1016/j.psychsport.2019.04.009

Toth, A. J., McNeill, E., Hayes, K., Moran, A. P., and Campbell, M. (2020). Does mental practice still enhance performance? A 24 Year follow-up and metaanalytic replication and extension. Psychol. Sport Exerc. 48:101672. doi: 10.1016/ j.psychsport.2020.101672

Valiente, C. (2019). Sport and social movements: lilí Álvarez in Franco's Spain. Int. Rev. Sociol. Sport 54, 622-646.

Vealey, R. S. (1988). Future directions in psychological skills training. Sport Psychol. 2, 318-336. doi: 10.1123/tsp.2.4.318

Vealey, R. S. (2006). Smocks and jocks outside the box: the paradigmatic evolution of sport and exercise psychology. Quest 58, 128-159. doi: 10.1080/00336297. 2006.10491876

Wachsmuth, S., Jowett, S., and Harwood, C. G. (2017). Conflict among athletes and their coaches: what is the theory and research so far? Int. Rev. Sport Exerc. Psychol. 10, 84-107. doi: 10.1080/1750984X.2016.1184698

Webdale, K., Baker, J., Schorer, J., and Wattie, N. (2019). Solving sport's 'relative age'problem: a systematic review of proposed solutions. Int. Rev. Sport Exerc. Psychol. 13, 187-204.

Weiss, M. R., and Gill, D. L. (2005). What goes around comes around: re-emerging themes in sport and exercise psychology. Res. Q. Exerc. Sport 76, S71-S87. doi: 10.1080/02701367.2005.10599291

Zhang, T., and Solmon, M. (2013). Integrating self-determination theory with the social ecological model to understand students' physical activity behaviors. Int. Rev. Sport Exerc. Psychol. 6, 54-76. doi: 10.1080/1750984X.2012.723727

Conflict of Interest: The authors declare that the research was conducted in the absence of any commercial or financial relationships that could be construed as a potential conflict of interest.

Copyright (c) 2021 Latinjak and Hatzigeorgiadis. This is an open-access article distributed under the terms of the Creative Commons Attribution License (CC BY). The use, distribution or reproduction in other forums is permitted, provided the original author(s) and the copyright owner(s) are credited and that the original publication in this journal is cited, in accordance with accepted academic practice. No use, distribution or reproduction is permitted which does not comply with these terms. 